\title{
Gobernanza ambiental y conservación: las gestiones del SERNANP y PROHVILLA en el Refugio de Vida Silvestre Los Pantanos de Villa ${ }^{1}$
}

Glendy León

doi: $10.46476 /$ ra.vi1.20

La conservación de los humedales, en especial de tipo costero, es importante no solo por los servicios ecosistémicos que brindan sino también porque permite contrarrestar los efectos del cambio climático. En el Perú, este tipo de humedales representa un $0.15 \%$ del total de superficie de humedales. Una de las causas que puede atribuirse a su degradación es a razón de una débil institucionalidad del Estado, ya que sus coordinaciones son desarticuladas y débiles en sus diferentes escalas de gobierno. Por ello, con el fin de lograr una adecuada gestión y promover su conservación, la Estrategia Nacional de Humedales-2015-del Perú ha propuesto fortalecerla. En ese sentido, se analiza la gestión unificada realizada por el Servicio Nacional de Áreas de Protegidas (SERNANP) y la Autoridad Municipal de los Pantanos de Villa (PROHVILLA) a fin de conocer si esta coadyuvó a la conservación de los Pantanos de Villa, y si, posteriormente, tenían herramientas normativas para proseguir con dicha gestión a favor de la conservación de esta Área Natural Protegida.

\section{Problema socioambiental de investigación}

El Refugio de Vida Silvestre Pantanos de Villa (RDVSPDV) ostenta un clima desértico con particularidades típicas de los desiertos tropicales, asociados con corrientes marinas frías (Cano \& Young, 1998, p. 5). Asimismo, posee 5 espejos

1. Tesis para optar por el título de Magíster en Desarrollo Ambiental (León 2019). 
de agua que pueden albergar hasta 210 especies de aves, 13 de peces, 5 de anfibios y reptiles. No obstante, de poseer riqueza natural, este refugio convive con contaminación antrópica a su alrededor. Desde el 2004, la Contraloría General de la República $\left(\mathrm{CGR}^{2}\right)$ ya había detectado hasta 7 puntos de vertimientos de efluentes líquidos (proveniente de locales de ganados-ovino/porcino- lavaderos de ropas y autos) que son vertidos directamente a canales tributarios de las lagunas de los Pantanos de Villa. Asimismo, existe arrojo de desmontes en la Zona de Reglamentación Especial (ZRE) que son echados, en su mayoría, en la avenida 12 de Octubre y cerca al local de la Asociación Civil Centro Cultural «Deportivo Lima» (CGR, 2004, pp. 14-15). No obstante, esta Área Natural Protegida (ANP) dispone de dos entes gubernamentales que velan por su gestión, motivo por el que debería realizarse una gestión articulada que denote una efectiva conservación del humedal.

De acuerdo con el Reglamento de la Ley de Áreas Naturales Protegidas, Ley ${ }^{\circ}$ 26834, aprobada mediante Decreto Supremo No 038-2001-AG, el Refugio de Vida Silvestre es un tipo de categoría que pertenece al Sistema Nacional de Áreas Naturales Protegidas (SINANPE) y por ende su gestión y administración recae en el Servicio Nacional de Áreas Naturales Protegidas (SERNANP); es decir, una entidad de competencia nacional. De otro lado, cuenta también con la Autoridad Municipal de los Pantanos de Villa (PROHVILLA), un organismo descentralizado de la Municipalidad Metropolitana de Lima, el cual cumple con las competencias de gestión y administración en la ZRE que se encuentra comprendida el ANP señalada; y con competencia municipal, de acuerdo con la Ordenanza $\mathrm{N}^{\circ} 1845$ 2014-MML.

\section{Metodología}

El diseño de la investigación es de tipo exploratorio y descriptivo. La recolección de información se hizo a través de fuentes primaria y secundaria (datos bibliográficos, fuentes normativas e instrumentos ambientales, tales como acciones de trabajo realizadas por el SERNANP y PROHVILLA), así como análisis cualitativo a los principales instrumentos ambientales como: Plan Director de Áreas Naturales Protegidas, e instrumentos de Planes Operativos y Memoria Institucional de PROHVILLA. Por ende, el objetivo de la investigación fue analizar la gestión y los elementos de coordinación interinstitucional del SERNANP y PROHVILLA en su área natural protegida, así como las acciones destinadas a la conservación del humedal costero, para la viabilidad de la gobernanza ambiental compartida.

2. Debe precisarse que, en mérito de lo dispuesto con el Informe $\mathrm{N}^{\circ}$ 208-2004-CG/MAC, la Gerencia de Medio Ambiente y Patrimonio Cultural de la Contraloría General de la República presentó un informe de auditoría denominado Pantanos de Villa: advirtiendo sobre la problemática para su conservación y preservación. 


\section{Hallazgos}

Hernández et al (2014, p. 219) mencionan que la colaboración interinstitucional es una expresión jurídica definida como la declaración de voluntades de dos o más partes para realizar de manera conjunta una acción en beneficio de todas las partes. En mérito a dicho precepto, la Municipalidad Metropolitana de Lima (MML) y el representante del Ministerio del Ambiente (MINAM), recaído en un funcionario del SERNANP, firmaron un convenio de colaboración interinstitucional el 02 de febrero de 2011, en vista de que ambas instituciones comparten la misma visión sobre los Pantanos de Villa: conservar el humedal de tipo costero del RDVSPV 3 . En esa línea, el objetivo de dicho convenio fue fomentar y promover la conservación de la diversidad biológica, la protección del ambiente y todas aquellas actividades orientadas al desarrollo sostenible de los recursos naturales (SERNANP, 2011, p. 1). Para lograr lo referido, realizaron los siguientes trabajos conjuntos:

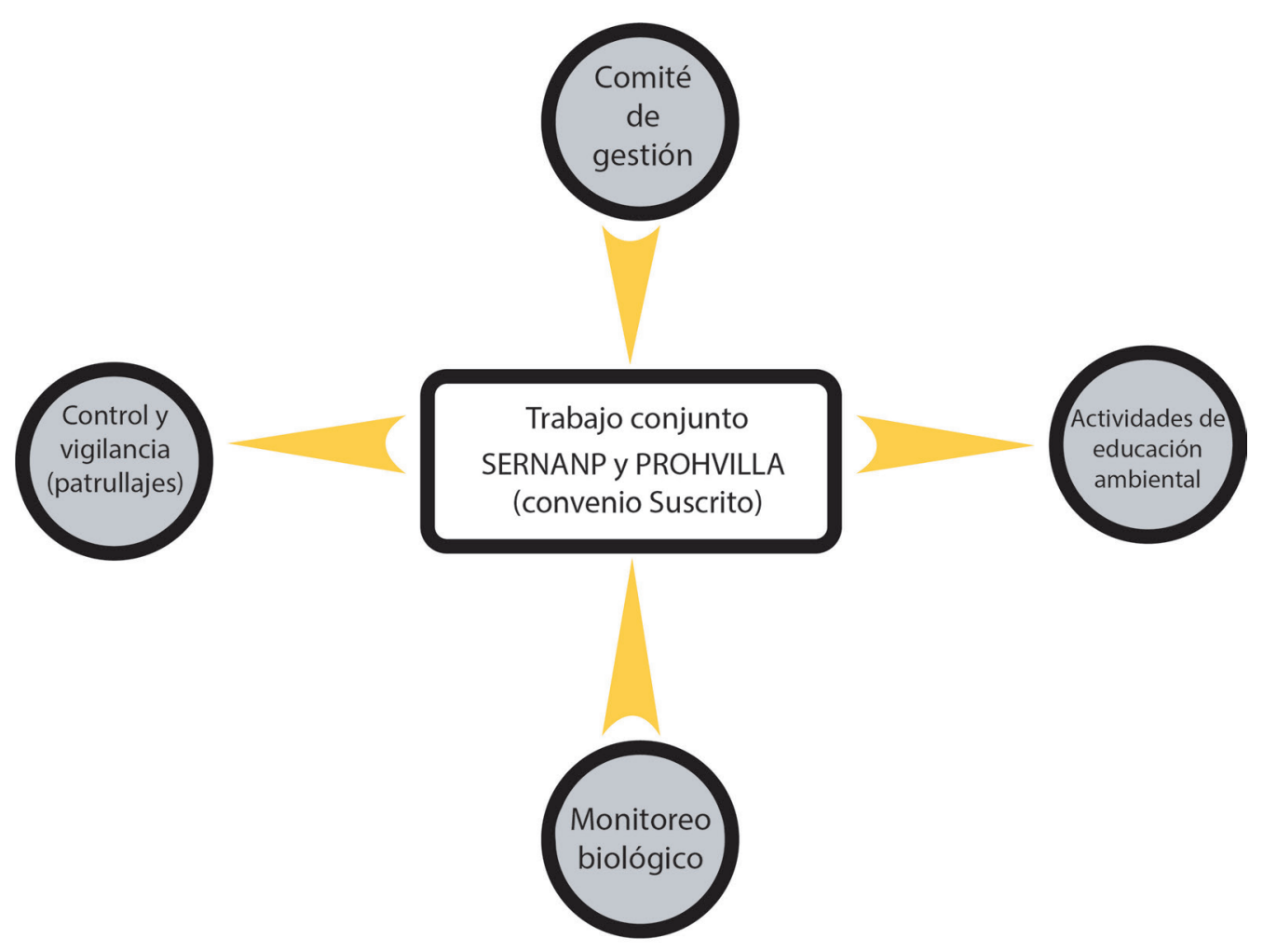

Figura 1. Actividades del trabajo conjunto celebrado entre el SERNANP y PROHVILLA. Fuente: elaboración propia en base a la Memoria Institucional Anual del Refugio de Vida Silvestre Pantanos de Villa, SERNANP, 2016.

3. Tanto SERNANP a través de la Resolución Jefatural No 169-2016- SERNANP como PROHVILLA a través de su Plan Operativo Anual del año 2017, comparten una misma visión. 
En especial, el trabajo conjunto realizado por personal de ambas entidades fue destinado a actividades como avistamiento de aves, medición de caudales y pruebas limnimétricas (que se realiza mensualmente cada 15 días), actividades de fiscalización con participación adicional de las municipalidades distritales (como Surco y San Juan de Miraflores) con la intervención de la Policía Ecológica en inspecciones especiales, y en actividades de educación ambiental. Asimismo, el Comité de gestión fue integrado por pobladores locales como los vecinos de la avenida 12 de Octubre y Las Delicias, el cual, juntamente con ambas entidades, conformaron grupos de trabajos en temas como vigilancia, canales y drenes; turismo, atención de riesgos y seguridad; y educación ambiental, lo que generó que sus reuniones se incrementaran de 5 a 22 cada año desde el 2010 al 2011, reconocimiento que le valió ganar el premio Globo Azul de la Red Mundial de Humedales por su buena gestión unificada en favor de los Pantanos de Villa. (Correo, 2014, 23 de octubre).

En conclusión, la participación de la gestión edil y del SERNANP, unificado en un solo representante como fue la figura del director Técnico, sumando la intervención de la población local (a través de la conformación de grupos de trabajos) y la participación de actores estratégicos como el Ministerio Público y la Policía Ecológica (en inspecciones diarias, nocturnas y especiales en el RDVSPV), coadyuvan a catalogarla, para el período del 2011 al 2014, como una práctica efectiva de la gobernanza ambiental. Sin embargo, dicho convenio no prosperó debido al cambio en la gestión metropolitana y municipal local, a pesar que esta nueva gestión, a fin de continuar con dicho convenio, contaba con herramientas normativas que impulsaban su gestión ambiental conjunta en favor de la conservación del recurso natural.

Al respecto, la Política Nacional del Ambiente ${ }^{4}$ yla Estrategia Nacional de Humedales (ENH) del año $2015^{5}$ son preceptos que guían normas, directrices e iniciativas del aparato institucional, las mismas disponen que, a través de una gobernanza ambiental, se puede preservar los recursos naturales como los humedales. En esa línea, la Ley $\mathrm{N}^{\circ}$ 29611, Ley General del Ambiente (LGA), en su artículo XI, trata a la Gobernanza Ambiental como un Principio conducente a la armonización de políticas, instituciones, normas, procedimientos, herramientas e información, de manera tal que la participación sea efectiva e integrada con los actores públicos y privados en la toma de decisiones, manejo de conflictos y construcción de consensos. Además, indica que las normas regionales y municipales, en materia ambiental, guardan concordancia con la legislación en el ámbito nacional y que las instituciones de esas escalas informan y realizan, de acuerdo con su Artículo

4 Aprobada mediante Decreto Supremo No 012-2009-MINAM

5 Aprobada mediante Decreto Supremo Nº04-2015-MINAM 
$61^{\circ}$, las coordinaciones con las entidades con las que comparten competencias y funciones antes de ejercerla. Tanto la LGA como la PNA, partiendo del enfoque institucional, deben ser comprendidas como complementarias y rectoras a toda disposición normativa ambiental para los tres niveles de gobierno.

En atención a lo descrito, la viabilidad y efectividad de estas normas rectoras se encuentran enmarcadas en las respuestas que brindan SERNANP y PROHVILLA en la gestión (acción y normas) de su ANP para contribuir con la disminución de la problemática detectada en la ENH.

A nivel normativo, la Ordenanza $\mathrm{N}^{\circ}$ 1845-2014-MML cumple en incorporar implícitamente el Principio de Transectorialidad, pues existen artículos definidos promocionados por la coordinación de estos dos entes. En cuanto al SERNANP, su Plan Director ${ }^{6}$, como instrumento máximo de orientación y planificación en el desarrollo del ANP, también lo regula en su numeral 2.3.8.1 Componente Orientador para la gestión, donde resalta la relación que tiene con cada uno de los actores intervinientes en las ANP y que son representados en la conformación del Comité de Gestión. De la misma forma, menciona que la gestión debe ser transectorial con los diferentes sectores del gobierno central que otorgan derechos sobre actividades o recursos de ANP, lo que constituye responsabilidad compartida entre el ente rector de las ANP y las diferentes autoridades sectoriales; así como responsabilidad propositiva cuando las instituciones públicas tienen injerencia directa sobre factores clave para la gestión del sistema.

En ese sentido, las principales normas de dichas entidades están dirigidas a fomentar la coordinación institucional cumpliendo, normativamente, el Principio de Transectorialidad.

La doble gestión diferenciada en el RDVPDV se convierte en un caso donde, a pesar que existen instrumentos normativos generales y especiales que fomenten su gestión conjunta a través de la coordinación, se aprecia que de no existir un documento donde se materialice dichos acuerdos, estos dos entes siguen realizando doble acción de trabajo (evaluación de avifauna, censos piezómetros; reglas limnimétricas en la calidad ambiental de los recursos hídricos, ruido ambiental), lo que ocasiona que cada institución almacene su propia información sin compartir una base de datos que diagnostique su situación actual y permita realizar planes de acción conjunta en favor de la conservación del RDVSPD, como fue realizada del año 2011 al 2014. Este mismo hecho denota que las entidades anteponen su competencia especial antes de preservar el bien común como es el recurso natural.

6. Aprobado mediante Decreto Supremo No 016-229-MINAM 


\section{Referencias bibliográficas}

Cano A., Young K.R. (1998). Pantanos de Villa. Biología y Conservación. Museo de Historia Natural. UNMSM. Serie de divulgación (11).

Contraloría General de la República (CGR). (2004). Pantanos de Villa: "Advirtiendo sobre la problemática, para su conservación y preservación. Lima, Gerencia de Medio Ambiente y Patrimonio Cultural. Lima. Consulta-16 de noviembre de 2017. https://apps.contraloria.gob.pe/wcm/publicaciones/medioAmbiente/ resultados-control/2004/Informe 208-2004-CG-MAC.pdf

Hernandez, D., Thomspson M., Brito L., y Lopez, M. (2014). Los convenios como herramienta para fomentar el desarrollo institucional en materia de investigación en salud. Revista de Especialidades Médico Quirúrgicas. (19). Consulta: 09 de enero de 2018. http://www.medigraphic.com/pdfs/quirurgicas/rmq-2014/ rmq142n.pdf

León, G. (2019). Gobernanza ambiental y conservación: las gestiones del SERNANP y PROHVILLA en el Refugio de Vida Silvestre Los Pantanos de Villa, y las acciones para su conservación. Pontificia Universidad Católica del Perú (PUCP). Recuperado de: http://tesis.pucp.edu.pe/repositorio/handle/20.500.12404/14122

Premio Globo Azul para los Pantanos de Villa por preservación del medio ambiente (23 de octubre de 2014). DiarioCorreo.pe. p. 1. Recuperado de: https://diariocorreo. pe/peru/premio-globo-azul-para-los-pantanos-de-villa-246406/

Servicio Nacional de Áreas Naturales Protegidas (SERNANP). (2011). Convenio de Colaboración Interinstitucional celebrado entre SERNANP y PROHVILLA. Lima, febrero. [CD-ROM-SERNANP] 
